\title{
Common Schools and Multicultural Education
}

\section{Citation}

Levinson, Meira. 2007. Common schools and multicultural education. Journal of Philosophy of Education 41, no. 4: 625-642.

\section{Published Version}

doi:10.1111/j.1467-9752.2007.00587.x

\section{Permanent link}

http://nrs.harvard.edu/urn-3:HUL.InstRepos:8454066

\section{Terms of Use}

This article was downloaded from Harvard University's DASH repository, and is made available under the terms and conditions applicable to Other Posted Material, as set forth at http:// nrs.harvard.edu/urn-3:HUL.InstRepos:dash.current.terms-of-use\#LAA

\section{Share Your Story}

The Harvard community has made this article openly available.

Please share how this access benefits you. Submit a story.

Accessibility 


\title{
Common Schools and Multicultural Education Meira Levinson Harvard Graduate School of Education
}

\begin{abstract}
$\underline{\text { Abstract }}$
Common schooling and multicultural education intuitively seem to be mutually reinforcing, and possibly even mutually necessary: each is motivated by and/or serves the aims of promoting social justice and equality, common civic membership, and mutual respect and understanding, among other goals. An examination of the practical relationship between the two, however, reveals that neither one is a necessary or sufficient condition for achieving the other; in fact, each may in certain fairly common circumstances make the other harder to achieve. In other words, there is no direct instrumental relationship between multicultural education and common schools. Nor is there a clear expressive relationship between the two. Although common schools may serve as explicit, public symbols of our multicultural civic commitment to diversity, mutual respect, and egalitarian inclusiveness, many demographically common schools neglect or even betray multicultural ideals, while many restricted entry and even segregated schools may express them better than most comprehensive and integrated schools. Hence, while multicultural education and common schooling do intuitively stand for similar, mutually reinforcing ideals, in practice they may be linked more closely in the confusions and dilemmas of implementation they both raise than in their mutual realization.
\end{abstract}

Richard Pring explains some of the goals and purposes of common schools as follows:

"The fight for the common school was essentially a moral one in terms of achieving greater social justice and equality, respect for persons and preparation for citizenship within a democratic order." Furthermore, the common school "is the place where people with different cultural traditions come together and are introduced to other cultures which the school or the educational service believes, in certain particular respects, to be superior or illuminating" (Pring, pp. $\mathrm{xx}$ and $\mathrm{xxx})$.

Christine Sleeter, an influential multicultural theorist in the United States, explains some of the goals and purposes of multicultural education as follows: "Multicultural movements ...challenge the United States [and presumably other countries, too,] to live up to its ideals of justice and equality, believing that this country has the potential to work much better for 
everyone. As tomorrow's citizens, children in schools should learn academic tools and disciplinary knowledge resources from vantage points of multiple communities. Further, young people should develop some sense of solidarity across differences that enables working toward closing the gap between the nation's ideals and its realities" (Sleeter 2005: 15).

These descriptions hew closely, to say the least. This shouldn't be surprising. Promoting inclusiveness and equality, reaching across difference, fostering mutual toleration and respect, enabling all students to achieve their highest potential, preparing citizens for a diverse society, creating a better world — these are all frequently appealed to as justifications for both common schooling and multicultural education. Intuitively, therefore, common schools and multicultural education seem to be mutually reinforcing. How better to achieve the aims of multicultural education than to ensure that students are educated in schools that welcome, respect, and enable the academic success of students from a wide variety of cultural backgrounds? How better to achieve the aims of common schools than to ensure that their curriculum, pedagogies, school culture, and practices are multicultural? It is hard to imagine how common schooling, done well, and multicultural education, done well, could be anything but mutually beneficial, even possibly mutually necessary.

My purpose in this essay is to push our imaginations a little further, to challenge our intuitions about the relationship between common schools and multicultural education. I start by querying the instrumental versus expressive relationship between the two, asking in section I if common schools are instrumental for realizing the aims of multicultural education, and the reverse in section II: is multicultural education instrumental for realizing the aims of common schooling? I demonstrate that each is neither a necessary nor a sufficient condition for achieving the other, and in fact that each may in certain fairly common circumstances make the other 
harder to achieve. Given the failure of the instrumental argument, section III addresses the idea that common schools may be expressive of the multicultural ideal: that they serve as explicit, public symbols of our civic commitment to diversity, mutual respect, and egalitarian inclusiveness. I agree that this relationship may hold in some schools, but point out that many demographically common schools neglect or even betray multicultural ideals, while many restricted entry and even segregated schools may express them better than most comprehensive and integrated schools. I end, therefore, by arguing that while multicultural education and common schooling do intuitively stand for similar, mutually reinforcing ideals, in practice they may be linked more closely in the confusions and dilemmas of implementation they both raise than in their concrete mutual realization.

\section{Common Schooling is Instrumental for Multicultural Education}

Sonia Nieto and Patty Bode define multicultural education as follows:

Multicultural education is a process of comprehensive school reform and basic education for all students. It challenges and rejects racism and other forms of discrimination in schools and society and accepts and affirms the pluralism...that students, their communities, and teachers reflect. Multicultural education permeates schools' curriculum and instructional strategies as well as the interactions among teachers, students, and families and the very way that schools conceptualize the nature of teaching and learning. Because it uses critical pedagogy as its underlying philosophy and focuses on knowledge, reflection, and action (praxis) as the basis for social change, multicultural education promotes democratic principles of social justice. (Nieto and Bode 2007: 44)

Given this definition, it is easy to imagine how and why common schools might be instrumentally necessary, or at least useful, in realizing multicultural ideals. As Pring shows us in his opening essay, for example, common schools in England represent a truly "comprehensive" (in both senses of the word) school reform in comparison to the selective schools they replaced. As common schools instead of just curricula or programs, they both 
symbolically and practically represent whole-school reform; to switch from selective schooling to common schooling is necessarily to change the character and practices of the school itself. Furthermore, common schools in the comprehensive model both welcome and attempt to serve a diverse body of learners and teachers; they are committed at least in theory to the educational success of all children, not just a select group. In the United States especially, too, they were founded with explicit civic and democratic purposes (see Reuben 2005; Macedo 2000; Tyack 2003), just as multicultural education aims for democratic equality, justice, and common civic membership. In all of these ways, then, common or comprehensive schools (I'll use the terms interchangeably) may be understood as working in tandem with multicultural education. And, it makes sense to think of multicultural education as setting the ends for which common schools may be thought of as an instrumental means. As Terry McLaughlin puts it, "The "common school' is regarded as valuable not as an end in itself but to the extent that it is an appropriate context for the realization of the underlying conception of common education" (McLaughlin 2003: 124). Selective and/or segregated schools, by contrast, may understandably be seen as an inappropriate context for realizing multicultural goals.

When we probe more deeply, however, and think especially about issues of pedagogy and socialization, then I think that common schools' instrumental relationship with multicultural education becomes much more problematic. Consider one incontrovertible aim of multicultural education, that of fostering all students' learning and academic achievement, so that "students from different racial, cultural, language, and social-class groups will experience equal educational opportunities.... [and] equal status in the culture and life of the school" (James A. Banks, "Series Introduction," in Sleeter 2005: viii). Many educational researchers have advocated "culturally congruent" (Gay 2000) or "culturally relevant" (Ladson-Billings 1994) 
teaching as an essential means for accomplishing this. "Pedagogical equality that reflects culturally sensitive instructional strategies is a precondition for and a means of achieving maximal academic outcomes for culturally diverse students" (Gay 1995: 28). The argument here is that students come in to the school with certain ways of thinking, speaking, interacting with adults, and relating to peers, as well as certain sources and types of knowledge, interests, skills, norms, and beliefs. Kevin, a twelve year-old white student who lives on the farm his grandparents started, may already know how to drive a car and repair a fence, expect in school to be given both substantial responsibilities and substantial freedom as he has on the farm, challenge his teacher and complains to his parents whenever he feels wronged, and think that value resides in deeds not words, just as his parents have taught him. He also may love videogames and IMing with his friends. Yasmin, a twelve year-old Dominican student who lives in a city, may know three different languages thanks to her family's frequent albeit involuntary moves, be restricted to playing inside to avoid the violence in her neighborhood, assume that her job in school is to follow teachers' orders without question, have extensive experience caring for young children, and think that value resides in storytelling and relationships, just as her parents have taught her. She also may love videogames and IMing with her friends. For Kevin and Yasmin to feel comfortable and welcome in school, to gain knowledge and skills they don't have, and to have the opportunity to demonstrate and build on knowledge and skills they do have, they will need schools and teachers who are responsive to and inclusive of these differences (as well as their similarities).

Culturally relevant instructional strategies may—and must—-therefore take multiple forms: being aware of what feels "natural" to students and responding appropriately, whether it be with respect to how students tell a story or make an argument, how they address people in 
authority, whom they view as being in authority, how they interpret and answer questions, or how they respond in cases of potential or apparent conflict; explicitly helping students master the "language of power" while remaining confident and comfortable with their own languages or linguistic practices (Delpit 1995; Levinson 2003); incorporating cultural symbols or resources from students' lives and cultures into the class as intrinsic components of the curriculum, not just add-ons (Ladson-Billings 1994); creating opportunities for students to use and share their own expertise in school so that they don't feel "ignorant" or disrespected; reaching out to parents and other family members in ways that build productive relationships as opposed to misunderstandings or hard feelings; and teaching students what they need to know to be emotionally, academically, economically, and politically successful in the twenty-first century. As this description suggests, culturally relevant teaching is challenging - especially if the student body is quite diverse. If students' incoming backgrounds, norms, and experiences are fairly homogeneous, then educators can relatively easily adjust their curriculum and practices to capitalize on their students' strengths and meet their students' needs. A school full of students like Kevin, for example, might ground each instructional unit in a challenging, real-world problem that students are responsible for solving in small groups, explain clearly when and why rules are in place to limit students' freedom, use examples from driving and farming as the basis for word problems in math class, proactively reach out to parents as educational partners, and explicitly teach students how and why clear, fluent, verbal communication is essential for success and hence required through frequent discussion, debate, and in-class presentations. A school full of students like Yasmin may take a very different approach because of her (and her peers') different backgrounds, strengths, and needs. In both cases, however, the school can 
establish a school culture, adopt pedagogies, incorporate content, and set policies that are culturally responsive and help students learn and thrive.

If the student body is extremely diverse, on the other hand, then such culturally responsive schooling is much harder to achieve. Teachers, schools, and educational authorities can only do so much to incorporate and respond to each students' background knowledge, skills, attitudes, beliefs, norms, aspirations, and needs. Hence, to the extent that educational equity is a central goal of multicultural education, and that this necessitates culturally congruent/relevant teaching, then selective schools that are culturally restricted or even segregated may actually be more conducive to successful multicultural education — at least as defined by cultural congruence and students' educational attainment - than are common schools that are culturally inclusive and integrated. (See Levinson 2003 for a related argument.) This may help explain, in fact, why many advocates of high quality education for poor, immigrant, and/or "minority" children have actually reduced or even ended their efforts to integrate schools, both calling for resources to be directed instead toward improving the de facto segregated schools these often students attend and also commending the often unacknowledged strengths that historically segregated schools may have demonstrated (Massey and Denton 1993; Ladson-Billings 1994; Siddle Walker 1996; Public Agenda Foundation 1998; Hochschild and Scovronick 2003; Levinson 2007; see also Foster 1997).

Common schools may also impede the achievement of other basic aims of multicultural education: namely, the achievement of mutual toleration, respect, and trust that are necessary preconditions for common civic membership, political cooperation, and democratic equality. I acknowledge that this claim is counterintuitive, to say the least. What better way is there for young people (and the adult citizens they grow into) to become "used to" each other (Appiah 
2006: 71) than to attend school with diverse "others" (Allport 1954; Pettigrew and Tropp 2000)? As I myself have argued, "it is hard for students to learn to be mutually tolerant and respectful of other people, traditions, and ways of life unless they are actually exposed to them. It is not enough to talk about tolerating others within the safety of mutually reinforcing, homogeneous groups" (Levinson 1999: 114). Nonetheless, there are reasons to think that common schools may not be instrumentally sufficient, necessary, or even useful for promoting these aims.

First, common schools that are not conscientious about and effective in building tolerant, mutually respectful, cooperative, and egalitarian relationships among its members can readily end up exacerbating tensions and prejudices rather than resolving or eliminating them. Merely bringing people together into a common space does nothing to help them get along, and in fact may inflame existing tensions as children (or adults) find themselves in close proximity with mistrusted, threatening, or even detested "others." Sadly, there is no shortage of examples of racially- or ethnically-motivated fights and even "race riots" in diverse comprehensive schools (and prisons - another public institution that brings diverse groups together often with little plan for fostering mutual respect). This anecdotal evidence - which in itself demonstrates that common schools aren't instrumentally sufficient for achieving the multicultural aims listed above - is buttressed by a wealth of empirical analysis showing that "the more we are brought into physical proximity with people of another race or ethnic background, the more we stick to 'our own' and the less we trust the 'other'" (see the lengthy list of references in Putnam 2007: 142).

Second, recent empirical evidence suggests that the mere experience of living in a diverse community—and also, one may hypothesize, of being educated in a diverse setting — may reduce all residents' civic engagement, trust, altruism, political efficacy, commitments to social justice, 
and realization of other, similar aims of multicultural education. In this case, it's not just trust of diverse "others" that is negatively impacted. Based on his analysis of a massive survey of 30,000 Americans across 41 communities, Robert Putnam argues, "inhabitants of diverse communities tend to withdraw from collective life, to distrust their neighbours, regardless of the colour of their skin, to withdraw even from close friends, to expect the worst from their community and its leaders, to volunteer less, give less to charity and work on community projects less often, to register to vote less, to agitate for social reform more, but have less faith that they can actually make a difference, and to huddle unhappily in front of the television" (Putnam 2007: 150-151, italics in orig.). If Putnam is right, then not only may diversity not be sufficient but homogeneity might actually be necessary for the realization of the multicultural aims listed above. On the other hand, of course, living in diverse communities and being educated in diverse common schools are very different experiences. It's quite plausible to think that common schools that treat diversity as an active good could not only avoid the negative outcomes that Putnam and others highlight but actually reverse these effects. In other words, thoughtful, intentional common schools might help transform students' experiences in their diverse communities into a good that leads them to become more engaged, trusting, and efficacious rather than less. I think this is a reasonable idea, and certainly a laudable aspiration. At best, however, this shows that common schools have the potential to be helpful, not that they necessarily are, or even that they are likely to be more helpful than homogeneous schools.

Third, common schools may impede students' development of mutual respect and deep cross-cultural understanding insofar as their visible sources of diversity may lead to complacency, whereby other sources of both diversity and homogeneity go unrecognized and unacknowledged. Consider, for example, a fairly typical school in San Francisco Unified School 
District: Alamo Elementary School. In October 2006 it had a student population that was about 44 percent Chinese, 20 percent non-Latino white, 13 percent "Other Non-White" (in this case meaning primarily Samoan), 5 percent Latino, 4 percent Japanese, 3 percent Filipino, 1 percent Korean, 1 percent African-American, 0.2 percent American Indian, and 11 percent unidentified. About one-quarter of the students are classified as English Language Learners, and a little over 31 percent qualify for free or reduced-priced lunch (San Francisco Unified School District 2006). This is an extremely diverse school by many measures, and also apparently a popular one: it gets a 10/10 rating and uniformly positive comments from parents on the "GreatSchools.net" website (GreatSchools.net 2007). I imagine that students, parents, and teachers take pride in Alamo's diversity and inclusiveness in addition to its many other fine qualities, and I would guess that teachers go to some effort to incorporate students' cultural backgrounds into their curriculum and pedagogical practices. One could imagine multicultural days in which students are encouraged to share or demonstrate special cultural practices, classroom libraries that include books of Mexican and Samoan folk tales, an interdisciplinary social studies and art unit that focuses on geography and scroll paintings in China, multilingual school publications, a genre study in literature that culminates with students' writing and "publishing" a biography of a relative, and many other thoughtful and well-planned approaches to recognizing and incorporating the diversity of ethnicities, cultures, languages, and family histories represented at the school. ${ }^{1}$

In the effort to be inclusive of the many cultures in the school, however, teachers may predictably neglect the many cultures, ethnicities, nations, religions, and so forth who are not in the school. In the presence of so much visible diversity, it can be difficult to focus on Others

\footnotetext{
${ }^{1}$ I'm also happy to imagine that Alamo engages in other culturally responsive practices, including reaching out to parents in a variety of ways, publishing the weekly newsletter in four different languages, ensuring the presence of translators at all parent-teacher conferences and school assemblies, explicitly teaching students the "language of power," and so forth. These practices, while incredibly important, are unrelated to the argument I am making here.
} 
who are not represented—say, African-Americans, South Africans, Iraqis, Swedes, or Muslims - as well as those who are potentially invisible, such as atheists or gays (well, outside San Francisco at least...). One can't teach everything, of course, and I'm certainly not advocating that Alamo Elementary try to cover all countries, continents, religions, sexual orientations, etc. That would be a recipe for educational incoherence. But it is a real danger in diverse common schools that teachers and students become complacent about their inclusivity. They fail to reflect on whether the groups they choose to focus on because they are represented in the building are the most significant ones for students to learn about—should American elementary school students in 2007 really know more about Samoa, for example, than about the Middle East? - and on the educational implications of neglecting certain kinds of diversity altogether, such as religion (Levinson and Levinson 2003) or ability. (Fewer than 7 percent of Alamo students are designated as needing special education.)

Furthermore, insofar as multicultural curricula are shaped around the "cultures" present in the school, students and teachers may end up treating each other as cultural representatives (Pollock 2004): turning to the Filipino students for the "Filipino perspective" on a topic, or to the African-American child for the "black perspective"- even if she's a ten year-old from California and the issue at hand is postcolonial Africa or the Harlem Renaissance in the 1920s. Even if educators are attentive to this danger, they may still teach about cultures or groups in such a way as to establish expectations of what is "normal," what members of this group are "supposed to" believe, do, or take pride in. As Anthony Appiah notes in this regard, "What demanding respect for people as blacks or as gays requires is that there be some scripts that go with being an African-American or having same-sex desires. There will be proper ways of being black and gay: there will be expectations to be met; demands will be made" (Appiah and Gutmann 1996: 
99) Diverse schools won't necessarily succumb to these faults, of course, but they are prone to them. In this respect too, therefore, common schools may fail to help students become respectful of and knowledgeable about "others," and thus fail to realize this fundamental aim of multicultural education.

Diverse common schools are thus not necessarily instrumental for multicultural education and may in some circumstances impede the achievement of multicultural goals. The diversity of the student body poses multiple challenges for designing and implementing culturally relevant curricula, pedagogies, institutions, and family and community outreach. In bringing diverse groups together, common schools may exacerbate tensions, misunderstandings, or worse, among members of these groups as opposed to fostering toleration and mutual respect. Common schools may do such a good job of attending to the visible diversity on campus that they discount or ignore important sources of diversity that are either not represented in the school or are invisible to the naked eye. Common schools may also respond to the visible diversity by treating students and teachers as "race (or culture) representatives," essentializing individuals and/or the groups to which they belong. Common schools do not have to do any of these things, of course; it's not that they are necessarily inimical to the realization of multicultural ideals. But it would be misguided to think that common schools are necessary or even predictably useful for achieving the goals of multicultural education.

\section{Multicultural Education is Instrumental for Common Schooling}

Perhaps, therefore, the relationship goes the other way. If common schools aren't instrumental for multicultural education, maybe multicultural education is instrumental for common schooling. Many of the multicultural failures of common schools that I described 
above, after all, might be taken instead to be failures to implement appropriate multicultural education. Common schools (and selective schools, for that matter) may end up failing to teach in a culturally congruent manner, essentializing particular cultures, neglecting the importance of groups who don't happen to be represented in the school, or getting caught up in "celebrations" of the visible aspects of culture to the exclusion of such invisible aspects as beliefs and values as well potentially invisible groups such as sexual minorities and the disabled. In fact, they are likely to do so- - which is exactly why good multicultural education is so important. James Banks, one of the most prominent US theorists of multicultural education, argues:

To implement multicultural education effectively, teachers and administrators must attend to each of the five dimensions of multicultural education. They should use content from diverse groups when teaching concepts and skills, help students to understand how knowledge in the various disciplines is constructed, help students to develop positive intergroup attitudes and behaviors, and modify their teaching strategies so that students from different racial, cultural, language, and social-class groups will experience equal educational opportunities. The total environment and culture of the school must also be transformed so that students from diverse groups will experience equal status in the culture and life of the school. (James A. Banks, "Series Introduction," in Sleeter 2005: viii)

It seems fairly uncontroversial to say that a school that does this would be a great school—and would also be unlikely to succumb to many of the dangers discussed in section I. Hence, multicultural education might well be thought of as instrumental, even necessary, for realizing the aims of comprehensive education. Multicultural education serves common schools, rather than vice versa.

This argument has some merit—but that is at least partly because the relationship between multicultural education and good education has been circularly defined into existence: Successful comprehensive schools (and all other schools, too) are those in which all children are given equal and excellent educational opportunities; multicultural education is that which enables schools to teach children equally and equitably so that they all learn and achieve; 
therefore, multicultural education is essential for successful comprehensive schools (and all other schools, too). Well, okay. But this doesn't tell us anything about multicultural education as such.

It's revealing in this context to look at how definitions of "multicultural education" have changed over time. When advocates and theorists of multicultural education were first trying to characterize what multicultural (or originally "intergroup" and then "intercultural") education meant, they tended to focus on curricular accuracy and inclusiveness (Banks 1993). In the United States, for example, multicultural educators mounted challenges to the overtly racist depictions of African-Americans in textbooks, challenging the depictions of "happy slaves," Little Black Sambo, the KKK as "savior" of the South, and so forth (Zimmerman 2004); they also pressed for the inclusion of more examples that " "properly present the contribution of the Negro to American culture"' (Zimmerman 2002: 112) and eventually of other demeaned and/or neglected groups as well (e.g. Native Americans, Latinos, Asian-Americans, and women) (Banks 1975). Over time, however, it became clear that inclusiveness was not enough. One could add numerous cultural fairs to the school calendar and sidebars to textbooks, but still fail to educate all children in an appropriate and equal fashion. Thus, as Banks explains the history,

A second phase of multicultural education emerged when educators interested in ethnic studies began to realize that inserting ethnic studies content into the school and teacher education curricula was necessary but not sufficient to bring about school reform that would respond to the unique needs of ethnic minority students and help all students to develop more democratic racial and ethnic attitudes. Multiethnic education, the second phase of multicultural education, emerged. Its aim was to bring about structural and systemic changes in the total school that were designed to increase educational equality. (Banks 1993: 20)

So definitions of multicultural education changed with the times. By the 1990s, American theorists of multicultural education were emphasizing the importance of "social reconstruction" (Grant and Sleeter 1999) in order to overturn racism, discrimination, and power inequities. In 
2001, for example, Banks argued that a primary goal of multicultural education must be "to help students acquire the knowledge, values, and skills they need to participate in social change so that victimized and excluded ethnic and racial groups can become full participants in U.S. society and so the nation will move closer to attaining its democratic ideals" (Banks 2001: 236).

In the past five years, with the federal "No Child Left Behind" law focusing attention on the "achievement gap" among students of different races, ethnicities, socioeconomic status, and special needs, multicultural education theorists have shifted again. It's not that they've abandoned their goals of restructuring society with multiculturally-oriented teachers' functioning as "agents of social change" (Banks 2001: 236). After all, Nieto and Bode's 2007 definition of multicultural education, quoted at the beginning of section 1 , clearly includes commitments to "comprehensive school reform," "social change," and "democratic principles of social justice." But these definitions are now generally framed within an entirely egalitarian framework. Thus Nieto and Bode start their section on the goals of multicultural education with the statement that

No educational philosophy or program is worthwhile unless it focuses on three primary concerns:

$>$ Tackling inequality and promoting access to an equal education

$>$ Raising the achievement of all students and providing them with an equitable and high-quality education

$>$ Giving students an apprenticeship in the opportunity to become critical and productive members of a democratic society (Nieto and Bode 2007: 10)

This strikes me as being right, and certainly upholds the historic and present goals of most advocates of common schools. But when one combines these goals with the definition of multicultural education quoted at top, it's entirely unclear what work the "multicultural" part of "multicultural education" is actually doing. Similarly, James and Cherry Banks' most recent definition of multicultural education is, "a field of study designed to increase educational equity for all students that incorporates, for this purpose, content, concepts, principles, theories, and 
paradigms from history, the social and behavioral sciences, and particularly from ethnic studies and women's studies" (Banks and Banks 2004: xii). Again, it's unclear what work the "ethnic" and "women's studies" is doing here beyond serving as window dressing. What if, for example, evidence from the social and behavioral sciences shows that educational equity is most effectively and efficiently achieved when schools set clear high standards, assess students frequently to measure their progress toward achieving the standards, and apply research-based instructional practices to address identified student needs - regardless of the insights that ethnic and women's studies have to offer? If a comprehensive school implemented these approaches and its students achieved at high and equitable levels, it is hard to understand what additional pull multicultural education would exert, or what it would have to add. Multicultural education has become a handmaiden to educational equity, not a distinctive enterprise in its own right. Thus, although it may be correct to view multicultural education as instrumental, and even necessary, for the success of common schools, this is only because its aims and practices have become definitionally indistinguishable from those of the common school in general.

\section{Common Schooling Expresses the Multicultural Ideal}

If common schools are not instrumental for multicultural education, and multicultural education is not instrumental for common schooling beyond its being definitionally posited as such, then perhaps the relationship is expressive instead. On this reading, even if (let's say) common schools are no more effective than selective/segregated schools at achieving multicultural education's goals, they are still important public expressions of our common commitment to these goals. Common schools stand as explicit, public symbols of our civic commitment to diversity, mutual respect, social justice, equality, and solidarity. We see their 
success as something for all of us to celebrate because common schools represent our nation writ small and our goals writ large. Their achievements are a source of common pride. Similarly, when comprehensive schools fail—when there is vast inequity in students' educational achievement, when students' race and school suspension and exclusion rates track each other all too closely, or when students emerge apathetic about social justice and indifferent to demanding claims of solidarity with Others - this failure shames us as a nation. Their failure is our common failure. From this perspective, it is crucial that we maintain comprehensive schools and strive for their success despite the challenges they pose because they serve as public expressions and reminders of our common civic values, goading us toward their achievement. (See Wingo 2003 for an insightful discussion of the civic functions of public symbols, including schools.)

I find this to be a compelling argument, up to a point. Public (state) schools do represent in important symbolic as well as practical ways the public's aspirational view of itself: who is included and excluded, what values and virtues are taught and expressed, what kind of community we think we are and hope to become. This is, of course, one major reason that public schools are such politically contested domains. So if public schools are "common" comprehensive schools, if their comprehensive status is understood to express a set of common multicultural values (such as diversity, mutual respect, and equality of opportunity), and if the public feels a sense of shame when these schools fail to realize these values in practice and a sense of pride when they do, then I would agree that common schools are expressive of the multicultural ideal. But these are three big "if"s. Let me address them in reverse order.

First, all too often the public does not actually feel ownership of or responsibility for public schools. When schools are judged as failures, politicians, journalists, other professionals, and citizens heap blame upon educators (most frequently teachers) and sometimes on "those" 
parents and students, as well. Many educators do this too, as Lisa Delpit eloquently explains in Other People's Children (Delpit 1995); unfortunately, not even all teachers and administrators feel the sense of ownership — and accompanying pride and shame — that we might wish for. In any case, when comprehensive school failure is seen as an occasion for blaming Others rather than for questioning and challenging ourselves as a community, then I think common schools are not actually serving an expressive function. Members of the public do not see these schools as demonstrative of the community's strengths, weaknesses, values, commitments, and aspirations, in which case these schools are solely instrumental — tools to achieve certain ends — as opposed to expressive. Furthermore, if or as failure mounts, even the ideals may start to seem more alien, and hence be more easily disavowed. Instead of simply blaming teachers for failing to teach, for example, citizens may start to blame the goals themselves, questioning the very purpose and aims of both multicultural and comprehensive education.

Second, if common schools are lauded merely for expressing multicultural ideals, rather than for actually achieving them, then there may be a risk of complacency similar to that which I discussed in section I. As schools "celebrate" their diversity - the number of languages their students speak at home, the number of countries their parents immigrated from, and so forththey may neglect to consider whether they are actually achieving the challenging aims of multicultural education. Are students mastering "disciplinary knowledge resources from vantage points of multiple communities" (Sleeter 2005: 15)? Do they consider the social justice implications of their actions? Do students know how to evaluate the normative implications of their actions and of those around them? Are they equipped to consider arguments, aesthetic creations, or cultural practices from multiple perspectives? Do they actually do so? My concern is that if the expressive function is taken as the entirety of the functional relationship between 
common schooling and multicultural education, then this celebration of the symbolic may in fact supplant the practical realization of multicultural ideals.

Third, equating the nonselective public school with the common school, and then equating the common school with the expression of the multicultural ideal, can distract one from the multicultural possibilities and pitfalls of nonselective and public, but de facto segregated, schools. This is an increasing problem throughout the United States and Europe (and likely elsewhere as well). In the U.S., one-third of black and Latino students overall, and over half of the black students in the Northeast, attend schools that have a 90-100 percent minority student population, while the average white students attends a school that is almost 80 percent white; these percentages have increased significantly over the past 15 years (Orfield and Lee 2006; see also Orfield, Eaton et al. 1996; Orfield 2001: Tables 14 and 18). Students are also segregated by class; for example, over 70 percent of the three million students in the four largest US school districts qualify for free or reduced price lunch (Dalton, Sable et al. 2006: Table A-9; U.S. Department of Education and National Center for Education Statistics 2002: Table 9), while many suburban school districts serve few poor children, as well as almost exclusively white students. School segregation is on the rise in Europe, as well (European Agency for Fundamental Rights 2007: Ch. 5). In England, "Segregation is now so extreme in some schools that there is not much further it can go" (Cowell 2006), with both white and non-white students attending schools that are substantially more segregated than would be predicted by their percentages of the population even at the local level (Johnston, Wilson et al. 2004). In Holland, schools have become increasingly segregated not only by religion (which has been true for decades) but also by social class and most recently by ethnic origin (Karsten, Felix et al. 2006). Roma students throughout Europe, Turkish students in Germany, North African students in 
France, and immigrant students and asylum seekers in many countries also frequently attend schools with a high degree of segregation - as do their white counterparts (European Agency for Fundamental Rights 2007: Ch. 5). Thus, it is important to recognize that many schools may be state-supported (public) and non-selective, and hence in theory "common," but still neither include nor represent (or "express") the diverse population. Even if they decry the existence of these schools, those who care about multicultural education also need to take them into account, especially since by all indications their numbers will be increasing in upcoming decades. If the "common" public school is assumed to be diverse and hence expressive of multicultural ideals, then the challenges (as well as the opportunities) that de facto segregated schools face in realizing effective multicultural education will likely be neglected, to everyone's detriment.

\section{Multicultural Education and Common Schooling Face Similar Challenges}

I have been using "common schools" and "multicultural education" in this article as if they have clear, accepted meanings as well as aims. This isn't true, of course. In fact, I would suggest that some of the possible inconsistencies and/or contradictions between common schools and multicultural education that I've raised either derive from or are expressive of lack of clarity about the scope and substance of these two ideas. This is not to suggest that if I had been clearer earlier on, many of these problems would have resolved themselves. To the contrary, I think that these conundra are built into the concepts of both common schooling and multicultural education. It is in the identification of these conundra, in fact, that we may gain the clearest understanding about what the relationship is between multicultural education and common schooling: not instrumental, nor expressive, but linked by the challenges they both face. I don't have room in this article even to describe (let alone address) these challenges in a way that does 
them justice, but I think it is worth at least sketching out a few to indicate where the dilemmas lie.

First, I suggest that both common schools and multicultural education are challenged by the dilemma of how to define the relevant community. How can and should each measure and address "diversity" and "difference"? What "groups" are treated as important in taking these measures - race, ethnicity, gender, class, nation, education level, immigration status, historical status, caste, primary language, religion... - and whose definitions of these groups applies? Also, even once groups are defined, how does one determine the scope of the relevant community? In determining how "common" a school truly is, should one compare the population of the school with the population of the local neighborhood? Across the city or county? Across the nation? Across the world? To whom is the common school responsible: students, parents, local residents, the nation, the world? Identical questions arise in determining what community multicultural education should prepare students to enter - and to help create.

Second, common schools and multicultural education each are defined by a set of practices as well as a set of goals. In both cases, the specifics are hotly contested among theorists: Can common schools be religious? What should multicultural education do or say about sexist or racist practices within particular cultures? How does one weigh the goals of antiracism education versus education for social mobility in determining the purpose of common schools or multicultural education? There are no easy answers to these questions, even if there are plausible stands that one may take. Furthermore, these practices and goals may stand in tension with one another. I suggested in section II that multicultural education suffers this problem with regard to "ethnic studies"; if students achieve equal and demanding educational outcomes and emerge committed to social justice without their curricula or teacher's pedagogies 
having been influenced by "ethnic studies," for example, then could advocates of multicultural education object? Would this be multicultural education, despite its failing to include recognizable multicultural practices? Similarly, a school may "look like" a common school (practice open enrollment, include a diverse student body across a range of measures, etc.) but fail to realize the goals of achieving high student achievement levels, an inclusive and respectful community committed to social justice, and "visibility" for each child. Is such a school appropriately understood to be a "common school"? If a private, highly selective, highly homogeneous school did achieve these goals, would it be more or less "common" than the first? Which school would be more admirable from the perspective of advocates of common schooling?

Finally, common schools and multicultural education face the same dilemmas regarding means-end breakdowns. If there is compelling evidence that comprehensive school reform is likely to lead to massive "white flight" (or "rich flight") to private schools, for example, then what should comprehensive school advocates do? If overt challenges to institutional racism lead students and parents to reject the whole idea of "multicultural education" and provoke protests against "radical" teachers and schools, then what should advocates of multicultural education do? Because common schools and multicultural education both seem to rely on the presence of a certain kind of community — diverse, inclusive — in order to create of a new one - egalitarian, mutually respectful, civically engaged and justice-oriented - they are especially challenged by this breakdown. In this way, as in the others, common schools and multicultural education are linked possibly more by the dilemmas they face than by anything else.

Common schooling and multicultural education are thus fraught with conceptual and practical predicaments that challenge each enterprise independently as well as in relation to one 
another. This fact should not call into question the ultimate value of their common goals. Equal educational outcomes for all students regardless of background, promotion of civic equality and social justice, respect for diversity, the production of civically motivated and engaged students, an end to racism, sexism, ableism, and other inappropriate forms of prejudice and discrimination — these goals of common schooling and multicultural education remain compelling and inspiring for many philosophers and educators, myself included. In deference to the importance of these goals, however, we should be hyper-attentive to the challenges of their realization, especially with regard to the relationship between common or comprehensive schooling and multicultural education. Neither one is a panacea for achieving the other; more to the point, each may actually make the other harder to achieve under certain circumstances. Although it is probably worth continuing to aim for their mutual realization-as I said in section II, it is hard for me to imagine a more desirable school or educational setting than one that simultaneously serves a diverse student body and attains the goals listed above - it is crucial that we remain attuned to the potential conflicts between common schooling and multicultural education, and not automatically assume that the one will enable or even assist in the attainment of the other. 


\section{REFERENCES}

Allport, G. W. (1954). The nature of prejudice. Cambridge, Mass.,, Addison-Wesley Pub. Co. Appiah, K. A. (2006). Cosmopolitanism: Ethics in a World of Strangers. New York, W.W. Norton.

Appiah, K. A. and A. Gutmann (1996). Color Conscious: The Political Morality of Race. Princeton, Princeton University Press.

Banks, J. A. (1975). Teaching Strategies for Ethnic Studies. Boston, Allyn and Bacon.

Banks, J. A. (1993). "Multicultural Education: Historical Development, Dimensions, and Practice." Review of Research in Education 19: 3-49.

Banks, J. A. (2001). Approaches to Multicultural Curriculum Reform. Multicultural Education: Issues and Perspectives, 4th Edition. J. A. Banks and C. A. M. Banks. New York, John Wiley and Sons, Inc.: 225-246.

Banks, J. A. and C. A. M. Banks (2004). Handbook of research on multicultural education. San Francisco, Jossey-Bass.

Cowell, A. (2006) "Islamic schools test ideal of integration in Britain." International Herald Tribune Volume, DOI:

Dalton, B., J. Sable, et al. (2006). Characteristics of the 100 Largest Public Elementary and Secondary School Districts in the United States: 2003-04 (NCES 2006-329). Washington, DC, U.S. Department of Education.

Delpit, L. (1995). Other People's Children. New York, The New Press.

European Agency for Fundamental Rights (2007). Report on Racism and Xenophobia in the Member States of the EU. FRA 2007, European Agency for Fundamental Rights. FRA 2007.

Foster, M. (1997). Black Teachers on Teaching. New York, The New Press.

Gay, G. (1995). Curriculum Theory and Multicultural Education. Handbook of Research on Multicultural Education. J. A. Banks and C. A. M. Banks. New York, Simon \& Schuster Macmillan: 25-41.

Gay, G. (2000). Culturally Responsive Teaching: Theory, Research, and Practice. New York, Teachers College Press.

Grant, C. A. and C. E. Sleeter (1999). Making Choices for Multicultural Education: Five Approaches to Race, Class, and Gender (3rd Ed.). New York, Wiley and Sons, Inc.

GreatSchools.net. (2007). "Alamo Elementary School - San Francisco, California - CA - school overview." Retrieved November 3, 2007, from http://www.greatschools.net/modperl/browse_school/ca/6335.

Hochschild, J. and N. Scovronick (2003). The American Dream and the Public Schools. New York and Oxford, Oxford University Press.

Johnston, R., D. Wilson, et al. (2004). "School Segregation in Multiethnic England." Ethnicities 4(2): 237-265.

Karsten, S., C. Felix, et al. (2006). "Choosing Segregation or Integration? The Extent and Effects of Ethnic Segregation in Dutch Cities." Education and Urban Society 38(2): 228-247.

Ladson-Billings, G. (1994). The Dreamkeepers: Successful Teachers of African American Children. San Francisco, Jossey-Bass.

Levinson, M. (1999). The Demands of Liberal Education. Oxford, Oxford University Press.

Levinson, M. (2003). "Challenging Deliberation." Theory and Research in Education 1(1): 23 49. 
Levinson, M. (2007). Hearing voices, telling stories: Communal constructions of civic identity. Unpublished manuscript (work in progress).

Levinson, M. and S. Levinson (2003). 'Getting Religion': Religion, Diversity, and Community in Public and Private Schools. School Choice: The Moral Debate. A. Wolfe. Princeton, Princeton University Press.

Macedo, S. (2000). Diversity and Distrust: Civic Education in a Multicultural Democracy. Cambridge, MA, Harvard University Press.

Massey, D. S. and N. A. Denton (1993). American Apartheid: Segregation and the Making of the Underclass. Cambridge, MA, Harvard University Press.

McLaughlin, T. H. (2003). The Burdens and Dilemmas of Common Schooling. Education and Citizenship in Liberal-Democratic Societies: Teaching for Cosmopolitan Values and Collective Identities. W. Feinberg and K. McDonough. New York, Oxford University Press: 121-156.

Nieto, S. and P. Bode (2007). Affirming Diversity: The Sociopolitical Context of Multicultural Education. Boston, Allyn and Bacon.

Orfield, G. (2001). Schools More Separate: Consequences of a Decade of Resegregation. Cambridge, MA, The Civil Rights Project, Harvard University.

Orfield, G., S. Eaton, et al. (1996). Dismantling Desegregation: The Quiet Reversal of Brown v. Board of Education. New York, The New Press.

Orfield, G. and C. Lee (2006). Racial Transformation and the Changing Nature of Segregation. C. R. Project. Cambridge, MA, The Civil Rights Project at Harvard University.

Pettigrew, T. F. and L. R. Tropp (2000). Does Intergroup Contact Reduce Prejudice? Recent Meta-Analytic Findings. Reducing prejudice and discrimination. Claremont Symposium on Applied Social Psychology and S. Oskamp. Mahwah, N.J., Lawrence Erlbaum Associates.

Pollock, M. (2004). Colormute : race talk dilemmas in an American school. Princeton, NJ ; Oxford, Princeton University Press.

Public Agenda Foundation (1998). Time to Move On. New York.

Putnam, R. D. (2007). "E Pluribus Unum: Diversity and Community in the Twenty-first Century -- The 2006 Johan Skytte Prize Lecture." Scandinavian Political Studies 30(2): 137-174.

Reuben, J. (2005). Patriotic Purposes: Public Schools and the Education of Citizens. The Public

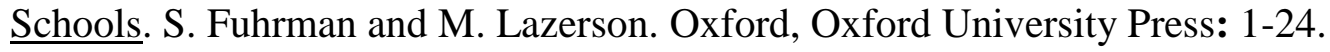

San Francisco Unified School District. (2006). "SFUSD Profile 2006-07: Alamo ES." Retrieved November 2, 2007, from http://orb.sfusd.edu/profile/prfl-413.htm.

Siddle Walker, V. (1996). Their highest potential : an African American school community in the segregated South. Chapel Hill, University of North Carolina Press.

Sleeter, C. E. (2005). Un-Standardizing Curriculum: Multicultural Teaching in the StandardsBased Classroom. New York, Teachers College Press.

Tyack, D. (2003). Seeking Common Ground: Public Schools in a Diverse Society. Cambridge, MA, Harvard University Press.

U.S. Department of Education and National Center for Education Statistics (2002).

Characteristics of the 100 Largest Public Elementary and Secondary School Districts in the United States: 2000-01. Washington, D.C., National Center for Education Statistics.

Wingo, A. H. (2003). Veil politics in liberal democratic states. Cambridge ; New York, Cambridge University Press. 
Zimmerman, J. (2002). Whose America? Culture Wars in the Public Schools. Cambridge, Mass., Harvard University Press.

Zimmerman, J. (2004). "Brown-ing the American Textbook: History, Psychology, and the Origins of Modern Multiculturalism." History of Education Quarterly 44(1): 46-69. 